\title{
Anthropometric measurements and the effect of breakfast sources in school achievement, physical activity and dietary intake for 6-13 years old primary school children girls in Makkah City
}

\author{
Hassan Mazher Bukhari \\ Dept. of Clinical Nutrition in the Faculty of Applied Medical Sciences, Umm al-Qura University Makkah, KSA
}

Email address:

hmyb2000@yahoo.com

\section{To cite this article:}

Hassan Mazher Bukhari. Anthropometric Measurements and the Effect of Breakfast Sources in School Achievement, Physical Activity and Dietary Intake for 6-13 Years Old Primary School Children Girls in Makkah City. International Journal of Nutrition and Food Sciences. Vol. 2, No. 6, 2013, pp. 272-279. doi: 10.11648/j.ijnfs.20130206.12

\begin{abstract}
Background: Many studies run in Saudi Arabia to seize obesity and food related diseases, but lack of data on anthropometric status and related health problems in primary school girls in western area promoted further research. Objectives: To determine the patterns of growth status on children, to compare between home and school breakfast with the consumption of macronutrient and minerals, physical activity. Methodology: A cross sectional study was carried out in randomly selected 165 students girls from 3 schools in Makkah in primary schools aged between (6 and 13 years). Their height and weight were measured and weight for age, height for age and body mass index (BMI) for age were calculated. The children's information was obtained by interview and $24 \mathrm{hr}$ recall was completed by mothers for accuracy. Frequencies, mean, SD, differences between groups using chi square test and $24 \mathrm{hr}$ recall dietary analysis, were measured by SPSS package (Version 16.0). Results: The prevalence of overweight and obesity, underweight, wasting, and stunting were $29.5 \%$, $20 \%, 20 \%$ and $11 \%$ respectively. Lower vitamin $\mathrm{B}_{12}$ intake was associated with stunting. There was association between underweight and stunting. The mean for the macronutrients was high, except for fat mean which was within RDI. Total calories come from carbohydrate 48.9\%, Protein 18.5\%, and Fat 32.6\%. A higher percentage of school breakfast consumers had low physical activity level compared to their counterparts (50.6\% vs. 28.8\%). Moreover, the former group had lower school achievement level vs. home breakfast consumers (89\%vs.57.8\%). Conclusion: Preventive measures should be instituted by health authorities to prevent further increase in the prevalence of overweight, wasting, and stunting in schoolaged children. It is becoming a priority to establish school and adolescent nutrition and health programmes, with the emphasis on increasing physical education and consumption of healthy diet.
\end{abstract}

Keywords: Anthropometry, Nutritional Status, Health, Primary School Children

\section{Introduction}

The definition of school age group corresponds approximately to the period from kindergarten through lower secondary schooling. Growth affects strongly with the family intake and food habits and consumption. It also indicates the effect of income and education on child care and supplying (Leslie, 1990).

A study in Saudi Arabia has sought to establish the prevalence data of malnutrition. They found that compared to data from other countries, the prevalence rate of malnutrition is still higher in Saudi children than other countries with less economic resources, indicating that more efforts are needed to improve the nutritional status of children. The prevalence of moderate and severe underweight was $6.9 \%$ and $1.3 \%$, respectively. The prevalence of moderate and severe wasting was $9.8 \%$ and $2.9 \%$, respectively. Finally, the prevalence of moderate and severe stunting was $10.9 \%$ and $2.8 \%$, respectively. The prevalence was lower in girls for all indicators. Comparison of the prevalence of nutritional indicators in selected countries demonstrates large disparity with an intermediate position for Saudi Arabia (El Mouzan et al., 2011)

Another study also was done in Saudi Arabia to establish the national prevalence of overweight and obesity in Saudi children and adolescents. This report establishes baseline 
national prevalence rates for overweight, obesity and severe obesity in Saudi children and adolescents, indicating intermediate levels between developing and industrialized countries. The overall prevalence of overweight, obesity and severe obesity in all age groups was $23.1 \%, 9.3 \%$ and $2 \%$, respectively.

In the United States government put programs in place to make sure each child has at least one healthy, balanced meal a day. This meal is usually breakfast, because the relationship between breakfast and improved learning has been clearly shown, programs are available in poor and underserved areas of the United States (Kliegman et al., 2007).

Therefore, our investigation aimed to determine the prevalence of stunting, wasting, undernourishment and obesity in girl children at school age from age 6-13 as well as study the relationship between sources of breakfast with food intake analysis by $24 \mathrm{hr}$ recall, physical activity and school achievement.

\section{Methodology}

Study design: The study was a cross-sectional and descriptive data which was collected in 2011 between $1 / 3$ and 24/5 from random sample from different areas in Makkah. A maximum of 60 students was assigned from each school. However, due to difficulty of obtaining this number, any convenient sample could be sufficient, At the commencement, a letter has been given to every school to indicate our objectives for conducting the research. Another letter has been handed to the parents of the children to seek consent for contribution.

Population: All schools follow the Ministry of Education curricula with two schools under the supervision of the governmental free education system and one consider as part of the private sector.

Study Sampling: Samples were obtained from students from each school, and sufficient students were taken from each school stage. An informed consent form was sent to all the parents of the children and principals of schools. Almost all (99\%) parents and school principals provided signed consent forms.

A sample size of 162 students was obtained randomly from the total population; all of them were girls between the ages of 6 and 13 years.

Material and equipments:

This is the list of equipments and materials which used in the study:

1) Digital electronic scale. 2) Height metal tape.

3) Nylon tape measure. 4) WHO Anthroplus program

5) Mother questionnaire 6) Child questionnaire.

The study Questionnaire:

Child questionnaire: contains five major parts: child demographic data, anthropometric data, nutritional data and eating habits, Physical activity data and school score.

Mother questionnaire: contained three major parts: personal data of mother and child, socioeconomic data and health of child, nutritional data of child.

Anthropometric measurements and anthropometric data analysis

1. Weight measurement: Weight was measured by the help of digital electronic scale. Weight was recorded to the nearest $0.1 \mathrm{~kg}$.

2. Height measurement: Height was measured by the help of a metal or nylon tape without shoes. Height Measurement was taken to the nearest $0.1 \mathrm{~cm}$.

3. Body mass index (BMI) was calculated by using the formula weight $(\mathrm{kg})$ divided by height $(\mathrm{m})$ squared.

4. Anthropometric indices: Body mass index for age (BAZ) was used to define overweight and obesity, and wasting, height-for-age (HAZ) was used for stunting, and weight-for-age (WAZ) for underweight.

The $24 \mathrm{hr}$ recall and food analysis by diet power (V.4) software:

Random 50 girls from our sample have been completed food analysis for the $24 \mathrm{hr}$ recall that was conducted by diet power software (version 4) for all meals over the day prior to the interview.

Reference standards:

1. The current study used for Height, weight and BMI and other data the newly recommended NCHS/WHO reference standards (Onis de $\mathrm{M}$ et al (2007); (NHANES II) of 1971-1974.

2. The reference for RDA intake for nutrients in calories, grams or $\mathrm{mg}$ from the $24 \mathrm{hr}$ recall was used according to AHA (2005) recommendations.

4-The physical activity reference standard: the Canadian Fitness and Lifestyle Research Institute (CFLRI) adopted the guideline for physical activity suggested by Corbin, Pangrazi, and Welk (1994).

Statistical package:

SPSS (V.16), 2008) was used to find frequencies and percentage, mean, $\mathrm{SD}$, To find the statistical significant difference for the association of two variables $\mathrm{X}^{2}$ test was used.

WHO Anthroplus software: The age, weight, length/height were the basic variables required to derive the most common nutritional status indicators for the children, i.e. weight-for-age (WAZ), height-for-age (HAZ), and BMIfor-age (BAZ).

Limitations: This study was done in high economic status and small region and in which majority of Saudi girls.

\section{Results}

One of the main important findings in this study summaries in figures (1,2, and 3), which show anthropometric measurements indices among the 6-13 years old children girls. According to anthropometric measurement indices, in this study, it was found that $20 \%$ of the sample was wasted, $11 \%$ were stunted and about $30 \%$ were overweight or obese.

In figurel Height for age index for the sample demonstrates that $60.7 \%$ of the children were normal height 
for age, and these were the biggest proportion. Followed by those who were tall (28.2\%). And only $11 \%$ were stunted. In figure 2 and 3 , it was found that $20 \%$ of the sample was underweight, $50.5 \%$ were normal weight and about $30 \%$ were overweight or obese.

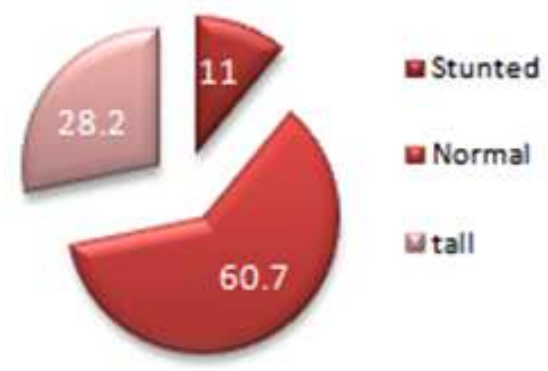

Fig 1. HAZ Height for age (stunting)\%

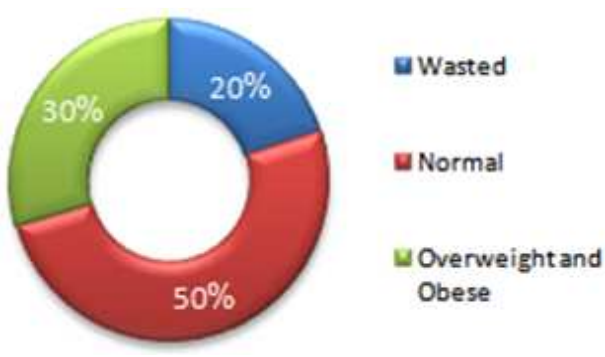

Fig 2. WAZ Weight for age(wasting)\%

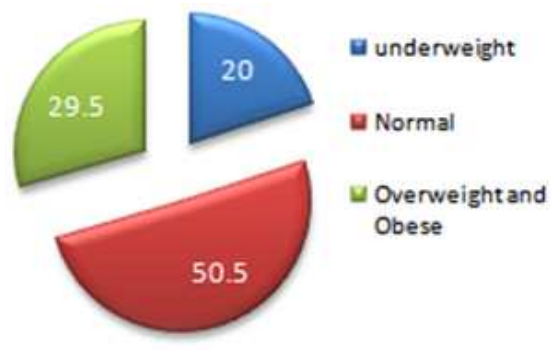

Fig 3. BAZ BMI for age (underweight) \%

When vitamin B12 intake studied in association with the level of height for age a significant difference $(p=0.043)$ was observed with about forty three $(42.9 \%)$ of tall children got lower vitamin B12 intake than recommended level (figure4). A close percentage (40\%) was found for the stunted children and lower than recommended level of vitamin B12 intake. However, less proportion of stunting children was found in the higher intake level compared to the tall group (40\% vs. $57.1 \%$ resp.). Most of normal height children consumed a higher level of vitamin B12 intake than recommended $(84 \%)$.

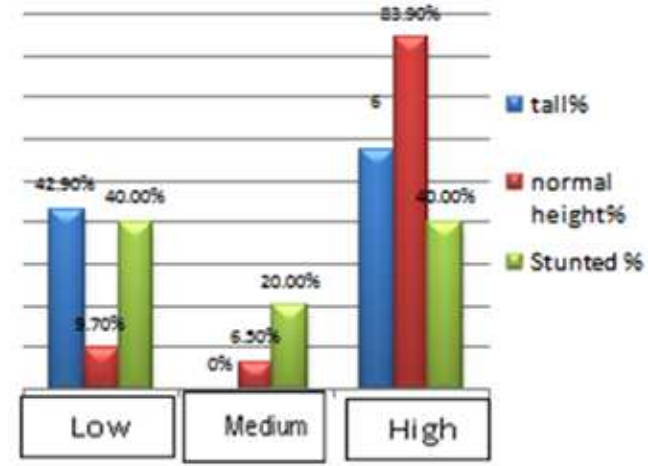

Fig 4. categories of height for age in association with vitamin B12 intake

When HAZ categories studied in association with the level of WAZ for age to find the sub-group of students who suffers from both being underweight and stunted, table 1 shows that a highly significant association was occur ( $p$ $<0.01$ ) between being a child who suffers from both being underweight and stunted represent $68 \%$ of the sample $(n=17)$. Tall children were in major found in the overweight and obese (46\%) group. However, about $60 \%$ of children had a normal weight and height.

Studying the analysis of the $24 \mathrm{hr}$ recall of food intake for the whole studied sample (table2) had shown that the mean of total calories/day was $1858 \mathrm{kcal} / \mathrm{d}( \pm 737)$. The mean of carbohydrate consumption per day was $228 \mathrm{~g} / \mathrm{d}$ ( \pm 112.4).protein mean of consumption was $131.1 \mathrm{~g} / \mathrm{d}$ $( \pm 397.2)$. With regard to mean of fat consumption was 67.4 g/ d ( \pm 73$)$. Total calories come from Carbohydrate 48.9\%, Protein $18.5 \%$, and Fat $32.6 \%$.

Figure 5 demonstrates that there was a significant difference occur $(p=0.029)$ when physical activity level studied in relation to the sources of breakfast. Less percentage of children who got their breakfast from home also had a lower physical activity level compared to children who got their breakfast from school $(28.8 \%$ vs.50.6\%). More than half the children who got breakfast meals from home also have a moderate physical activity level compared to $30.3 \%$ of those who got meals from school.

Table 1. Association between categories of HAZ and WAZ for level of risk in children.

\begin{tabular}{|c|c|c|c|c|c|c|}
\hline \multirow{2}{*}{ Categories of $\mathrm{Ht}$ for $\mathrm{A}$} & \multicolumn{3}{|c|}{ Categories of weight for age } & \multirow{2}{*}{ Total } & \multirow{2}{*}{$X^{2}$} & \multirow{2}{*}{ P value } \\
\hline & Over-weight and obese & Normal weight & Under-weight & & & \\
\hline Tall & $45.5 \%(5)$ & $45.5 \%(5)$ & $9.1 \%(1)$ & 11 & \multirow{4}{*}{29} & \multirow{4}{*}{0.0001} \\
\hline Normal ht & $23.7 \%(14)$ & $59.3 \%(35)$ & $16.9 \%(10)$ & 59 & & \\
\hline Stunted & $0 \%(0)$ & $32.0 \%(8)$ & $68.0 \%(17)$ & 25 & & \\
\hline Total & (19) & (48) & (28) & 95 & & \\
\hline
\end{tabular}


Table 2. Mean, $S D$ for calories, carbohydrate, protein, and fat from $24 \mathrm{hr}$ recall $(n=50)$.

\begin{tabular}{|c|c|c|c|c|}
\hline Statistics tests & Calories (kcal/d) & Carbohydrate (g/d) & $\begin{array}{c}\text { Protein } \\
(\mathrm{g} / \mathrm{d})\end{array}$ & $\begin{array}{c}\text { Fat } \\
(\mathrm{g} / \mathrm{d})\end{array}$ \\
\hline Mean & 1858 & 227.6 & 131.1 & 67.4 \\
\hline Std. Deviation & 736.5 & 112.5 & 397.2 & 72.9 \\
\hline$\%$ from total calories & - & $48.9 \%$ & $18.5 \%$ & $32.6 \%$ \\
\hline Recommended intake level by age (DRI) & $1200-1600$ & $113-142$ & $19-34$ & $39-85$ \\
\hline
\end{tabular}

$\mathrm{DRI}=$ Dietary references intake.

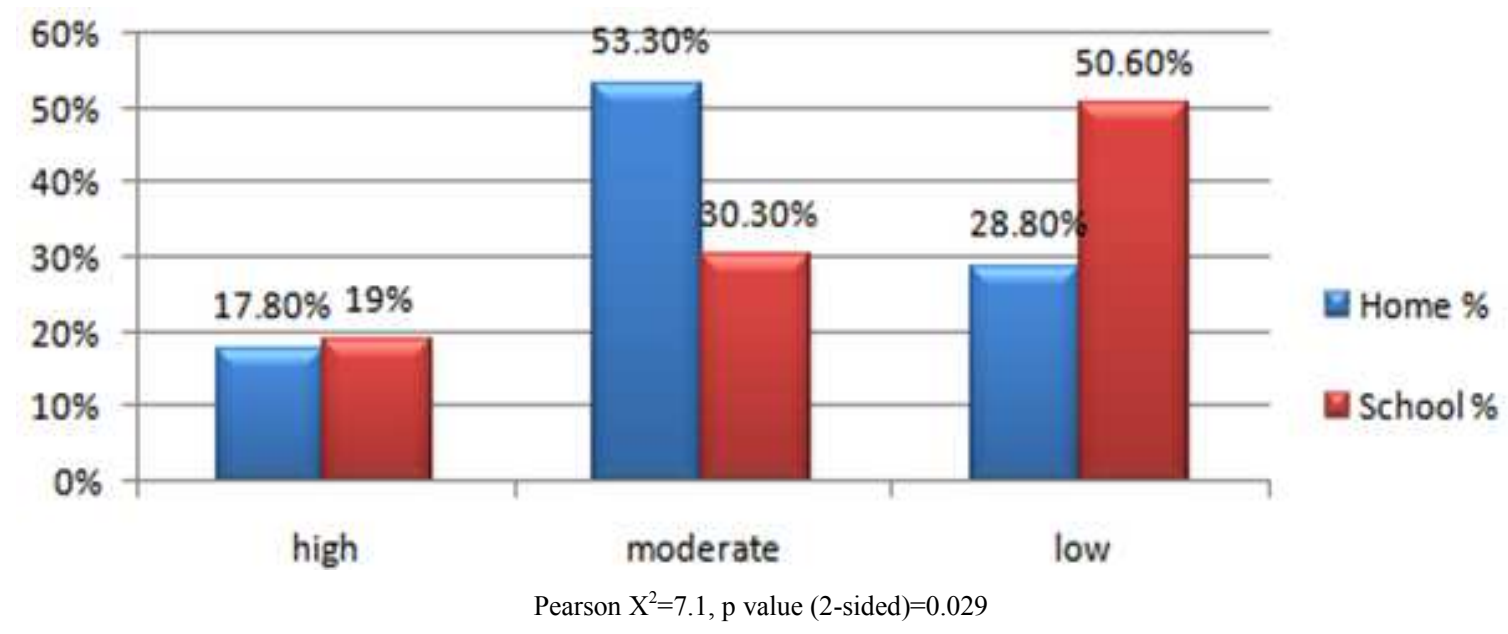

Fig 5. Sources of breakfast in association with physical activity level among 6-13 years old children girls

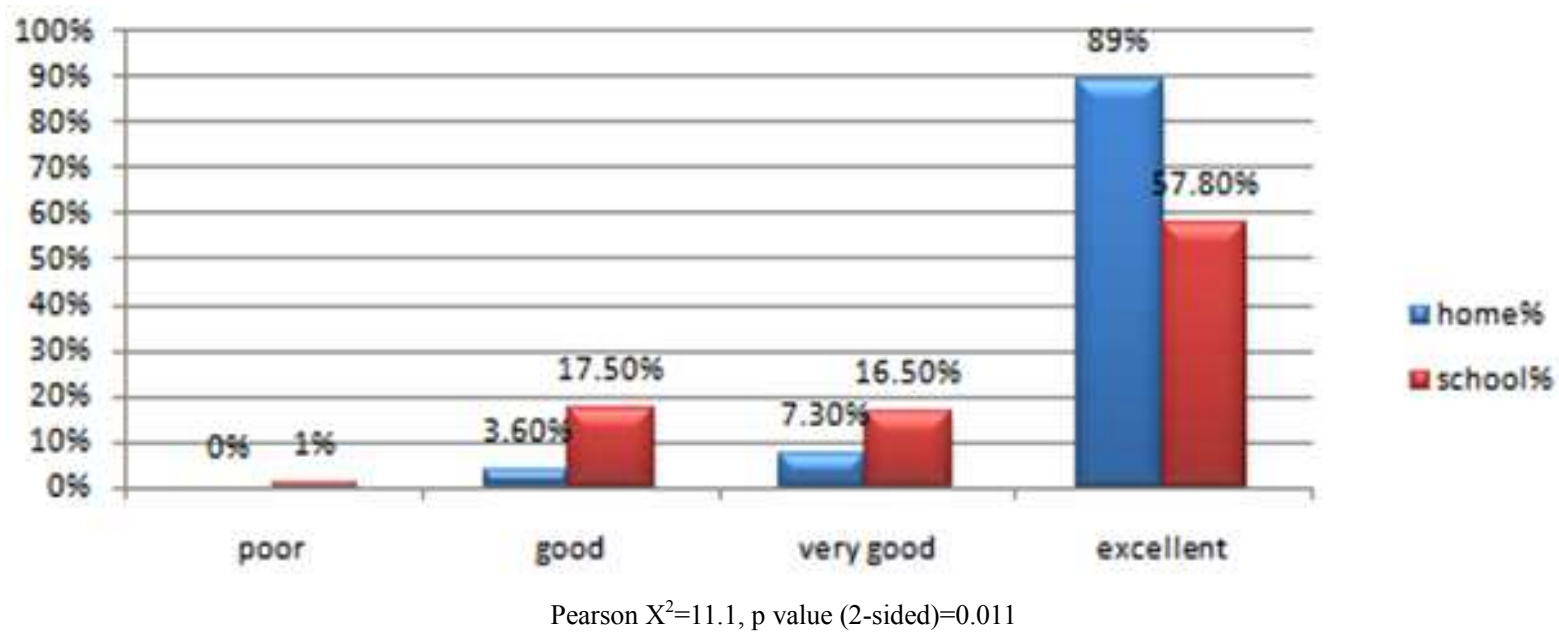

Fig 6. Sources of breakfast in association with school achievement among 6-13 years old children

Both groups of breakfast sources have almost the same percentage of high activity level $(17.8 \%$ and $19 \%$ for home and school breakfast resp.

Figure6 indicates that there was a significant difference occur $(\mathrm{p}<0.01)$ when school achievement level studied in association with the sources of breakfast. Higher proportion of children (89\%) who get home breakfast have achieved excellent grading compared to only $58 \%$ of the children who get school breakfast. This leaves more children who get breakfast from school in lower grading as follow; $16.5 \%, 17.5 \%$ and $1 \%$ in very good, good and poor performance categories respectively compared to $7.3 \%, 3.6 \%$ and $0 \%$ respectively in the same categories for children with meals from home.

\section{Discussion}

When it comes to the weight defined by BMI for age lower than $>+1 \mathrm{SD}$, in this study it shows that the prevalence of overweight and obesity combined together in these children is higher compared to several Saudi studies (29.5\% vs. $14-19 \%)$ respectively (El-Hazmi and Warsy, 2002).

Similarly, in a recent study in Turkey, a lower prevalence of overweight or obesity (only 3\%) was found in girls aged between 6-12 years (Bilgili et al., 2009). Several studies 
have reported prevalence of overweight or/and obesity in school children with ages ranging from 7- 14 years in Riyadh (El-Hazmi and Warsy, 2002), and in Australia also reported a coexistence of a relatively higher than expected prevalence of overweight/obesity and undernutrition among children from 3 - 12 years (Renzaho, 2006).

In a report from a representative sample of US children collected between 2003 and 2006 using cut-off values similar to those of the WHO, the prevalence of overweight and obesity in children 2 to 19 years of age was $31.9 \%$ (Ogden et al. 2008). This was very close to the prevalence rates of $29.5 \%$ for overweight and obesity reported in this study. This is not the case if a comparison with prevalence of overweight and obesity of (23.9\%) (20.4\%) respectively, in 2007 World Health Organization (WHO, 2007) and Center for Disease Control (CDC, 2000) references has been accomplished, which shows that our finding appears much higher.

This could be attributed to the fact that children start going to school at early age, and hence, there is a less control on their eating habits and nutrition at this stage. Moreover, children in our country have become less active; few or none walk to school, spending more time in sedentary entertainment activities, such as viewing TV, computer and video games. On average, a child in Saudi Arabia spends 6 hours per day in front of screens (Baker et al., 2005). Nevertheless, $50.5 \%$ and $20 \%$ of them were with normal weight and underweight respectively. Previous research in Saudi Arabia has documented approximately the same findings (Al-Dossary et al. ,2010).

The prevalence of stunting was $11 \%$ in the current study. In a report from the West Bank, Palestine, the prevalence of stunting in school children was 7.3\%, in Ramallah and; $4.2 \%$ in Hebron (Mikki et al. 2010). These values are much lower than our results $(11 \%)$ irrespective of the reference used. However, the sample in that study was not national, and the reference was used to define stunting as height for age less than the third percentile, which roughly corresponds to -2 SD (Cole et al. 2000). However, the current prevalent stunting level is lower than that found by the Fesharkinia et al recent study in Iran (2009) which found that $13 \%$ of the sample was stunted.

A report on stunting in Indian adolescents aged 11-16 living in South India that compared them with a sample from the same ethnic background but living in Dubai, United Arab Emirates (UAE), using the 1978 NCHS/WHO reference, revealed a prevalence of stunting of $36.9 \%$ living in India, compared to $11.6 \%$ for South Indian students living in the UAE (Haboubi and sheikh, 2009). The other finding of that report is the marked difference in prevalence of stunting, an indicator of chronic malnutrition, between the two samples of the same ethnic origin, but living in different demographic and socioeconomic environments.

This observation is in line with previous reports suggesting that most of the national variability in stunting can be explained by socioeconomic and demographic factors, and that improvement of socioeconomic status led to marked improvement of nutritional status in general and a marked decline in the prevalence of stunting in children less than 5 years of age with expected positive effects on the stature of older children (Frongillo et al.,1997 ; Monteiro et al.,2010) .

A cross-sectional study from eight provinces in China revealed a prevalence of stunting in the age group of 10-18 years $(23 \%)$ in 1991 , which decreased to $19 \%$ in 1993 (Wang et al. 1998) .Using the 1978 NCHS/WHO reference, the prevalence of stunting (defined as height for age $\mathrm{z}$ score $<-2 \mathrm{SD}$ ) in a rural region of South Africa was reported to be between $5 \%$ and $7 \%$ in children and adolescents 5-20 years of age (Kimani-Murage et al. ,2010). Similar prevalence levels of $5.7 \%$ were reported from Turkey in school children 6-16 years of age (Gür et al., 2006), whereas a study in rural Pakistan has reported that a prevalence of stunting was $16.5 \%$ in school children 6-12 years of age (Khuwaja et al.,2005).

Underweight cannot distinguish between a child that is small in weight relative to his/her height and a child that is low in height relative to his/her age, but who may be normal in weight-for-height. On the other hand, wasting is an indicator of acute undernutrition, the results of more recent food deprivation (WHO, 1995).

In addition, it was found in the current study that about $20 \%$ of the children suffered from wasting, and the same proportion found for underweight category. In one study in Saudi Arabia $14.8 \%$ of children were wasted (El Mouzan et al. 2011).

De Onis et al (2004) study to estimate underweight in the world found a decreasing trend as anticipated by year 2015 with percentage in all developing countries to be $19 \%$ and in developed region to be $0.9 \%$ only. Thus, with the figures of this study of underweight, it is indicated that the projection was not achieved yet for Saudi Arabia as a country in a stage of shift from developing to be a developed one.

These finding is also opposed to the result of a recent Iranian study in elementary school children to measure effect of zinc deficiency in normal growth, which found that underweight proportion is about $7 \%$ and wasting about $5.5 \%$, (Fesharkinia et al recent study, 2009). Shariff, Bond and johson (2000) study about the prevalence of overweight among low-income school children in Kuala Lumpur proved that underweight and stunting are more prevalent than wasting in primary school children (6-10 years old).

In the current study, both stunting and underweight is found concurrently in $68 \%(n=17)$ of children. Prevalence of underweight and stunting separately in a sample of small children in Peru living in a poor area were 10.5 and $34.5 \%$ respectively, meanwhile presence of both in the same child was 9.3\% (Casapía et al, 2006). Thus, in our sample a higher percentage occur even though total number of children is small $n=17$.

Presence of stunting and underweight concurrently might lead to increased likelihood to have osteoporosis and the 
effectiveness of the immune system may be decreased (Popkin et al.,1996). This might lead in the long run to dizziness, swollen and bleeding gums, decaying teeth, muscle weakness, bloated stomach fatigue and low energy, problems learning, slowed reaction times and trouble paying attention. Additionally, children and adolescents who experience a sudden weight loss may be showing symptoms of Diabetes Type 1 (Gavin, 2009; Hunger and malnutrition report from (http://kidshealth.org/parent/misc/reviewers.html)

In a cohort study in Kenya, B12 intake was positively and significantly correlated with height $(\mathrm{P}<0.02)$ (Neumann et al. ,1987). Our data shows a similar pattern, where it was found that there is a significant association between vitamin B12 intake and height for age in children ( $\mathrm{P}<0.04)$. In other words, lower vitamin B12 intake was associated with stunting. Previous study in India has documented the same finding (Osei et al. ,2010) .This might be due to the rules of vitamin B12 which promotes growth in children; hence, low intake can lead to more growth retardation pattern such as stunting.

Some studies proved underweight and stunting together as a form of malnutrition which are more prevalent than wasting in primary school children 6-10 years old (Shariff et al.,2000). Our findings were on the same line with Gharib and Rasheed, (2009) (underweight and stunting together $31 \%$ vs. wasting $20 \%$ ), and the explanation by the study suggested a genetic control on height. Furthermore, the results showed that both stunting and underweight status in children were exist in the current sample, that could be explained by environmental control, which affect the children in early stages that goes back to infancy life with severe insult on the mother and infant nutrition.

When school achievement level studied in association with the sources of breakfast there was a significant difference occur $(p=0.011)$. Higher proportion of children $(89 \%)$ who get home breakfast have achieved excellent grading compared to only $58 \%$ of the children who get school breakfast. This leaves more children who get breakfast from school in lower grading as follow; $16.5 \%$, $17.5 \%$ and $1 \%$ in very good, good and poor performance categories respectively compared to $7.3 \%, 3.6 \%$ and $0 \%$ respectively in the same categories for children with meals from home.

From the School-based Health Interventions and Academic Achievement, Healthy Students, Successful Students Partnership Committee report (2009), it is clear that poor nutrition has a higher effect in poor achievement with $34 \%$ of students who does not eat breakfast get lower score at class. However, the highest proportion (71\%) came from not eating fruit and vegetables as recommended by ADA or five a day campaign.

In this study there was a significant difference occur $(p=0.029)$ when physical activity level studied in relation to the sources of breakfast. Most of the children who got their breakfast from home also had a higher physical activity level compared to children who got their breakfast from school (71.3\% vs.49.3\%) respectively, when moderate and high activity levels were combined. This in longer term could end into obesity and health risk on those children who eat from school, particularly, if the school meals are higher in fat and calories contents.

It was found in the study that the mean of calories was higher than recommended intake (mean $1858 \mathrm{kcal} /$ day, $( \pm 737)$, while the normal range is $1200-1600 \mathrm{kcal} /$ day. This was also higher than the findings of the school meal in American study by Perry (2008), with $1689 \mathrm{kcal} /$ day for the same age groups. This could be evidence that the children, although did take enough calories from the food they eat, yet, this cannot explain the stunning and wasted found in the sample.

Carbohydrate mean was $227.6 \mathrm{~g} / \mathrm{d}( \pm 112.5)$ in the study which was way above the standard range which was 113$142 \mathrm{~g} / \mathrm{d}$. Additionally, it is like the finding of Perry thesis with $231 \mathrm{~g}$ CHO consumption daily. It was indicated in previous studies that the children who have high level of CHO consumption were overweight or obese.

Similar profile of consumption was noticed with protein in the study where it was $131 \mathrm{~g} / \mathrm{d}( \pm 397)$ that was more than four times normal range of 19-34 g/d. These children in Saudi Arabia consumed far too higher than recommended level of intake for protein consumption on comparison to counterparts in America who are closer to RDI (61g/day). This might be explained under the light of that the children who have a high protein level daily are coming from high-income family, where it was a very common concept that higher meat consumption is related to the higher income level.

It was unanticipated to find that fat consumption belongs to standard range which is $39-85 \mathrm{~g} / \mathrm{d}$ and our study sample which was $67.4 \mathrm{~g} / \mathrm{d}( \pm 72.9)$. Thus, children should not increase the fat level more than that RDI range to avoid early obesity and heart diseases. Again, children in Saudi Arabia consumed higher than RDI recommended level of intake for fat consumption on comparison to children in America (60g/day).

A higher than recommended caloric contribution due to fats $(32.6 \%)$ and proteins $(18.5 \%)$ and carbohydrates $(48.9 \%)$. And this is not coincide with a study that was done about dietary habits and nutritional status of school aged children in Spain that found $40 \%$ of calories comes from fat and $16 \%$ from protein and $44 \%$ from carbohydrate (Juan et al.2006) . In our study the high protein consumption can be interpreted by the predominant intake of plant origin food.

\section{Conclusion}

Among this sample of primary school children (6-13 years old), normal children were more prevalent than others, where overweight and obesity have higher prevalence than stunting, wasting and underweight. Some of Makkah residents are from ethnic groups with short stature; consequently the stunting was higher in the sample, which 
was combined with being underweight. As a result, that was reflected negatively on the children health and normal growth. Therefore this result might be applied on most Makkah regions. Lower vitamin B12 intake was associated with stunting, which increase the magnitude of the problem.

There was a significant difference between sources of breakfast, PAL, and between source of breakfast and school achievement.

Preventive measures should be instituted by health authorities to prevent further increase in the prevalence of overweight, wasting, and stunting in school- aged children and the associated health hazards .It is becoming a priority to establish preschool, school and adolescent nutrition and health programmes, with the emphasis on increasing physical education hours and consumption of healthy food, by incorporating health messages into the school curricula.

\section{Acknowledgment}

Many thanks go to the help and support of these students who have collect the data and made the measurements with drafting of writing; Nawal Al-Shehri, Wejdan Kadah, Sara Al-Huthali, Aishah Aseri and Ferdos Ibrahim.

\section{References}

[1] American Heart Association. "Dietary Recommendations for Children and Adolescents. A Guide for Practitioners: Consensus Statement From the American Heart Association." Scientific statement endorsed by AAP. Circulation, vol. 112, 2005, pp. 2061-2075.

[2] Al-Dossary S, Sarkis P, Hassan A, EZZ El Regal M , Foud ${ }^{\mathrm{a}}$ A, (2010). Obesity in Saudi children: a dangerous reality, eastern Mediterranean health journal.

[3] Baker S et al. (2005). Overweight children and adolescents: a clinical report of the North American Society for Pediatric Gastroenterology, Hepatology and Nutrition. Journal of Pediatric Gastroenterology and Nutrition, 40:533-543.

[4] Bilgili N, Küçükerdönmez O, Köksal E and Ayaz A. (2009). Assessment of Body Composition and Serum Lipid Profile in School Children. Pakistani Journal of Medical Sciences. vol; 25(3): 468-473.

[5] Cole T, Bellezzi M, Flegal $\mathrm{K}$ and Dietz W. (2000).Establishing a standard definition for child overweight and obesity worldwide: International survey. $\mathrm{Br}$ Med J.;320:1240-3.

[6] De Onis, M.; Blössner, M; Borghi, E.; et al , (2004). Estimates of Global Prevalence of Childhood Underweight in 1990 and 2015, JAMA.; 291:2600-2606.

[7] El-Hazmi MA, Warsy AS (2002); A comparative study of prevalence of overweight and obesity in children in different provinces of Saudi Arabia. J Trop Pediatr.Jun;48(3):172-7

[8] El Mouzan M , Al Herbish A, Al Salloum A, Foster P, Al Omer A , and Qurachi M. (2011). Prevalence of short stature in Saudi children and adolescents, Annals of Saudi Medicine, (5): 498-501
[9] Fesharakinia, A, Zarban, A. and Sharifzadeh, GR, (2009). prevalence of zinc deficiency in elementary school children of south khorasan province (eastern Iran), Iranian journal of pediatrics. ; vol 19(3), pp 249-254.

[10] Frongillo EA, Jr, de Onis M,and Hanson KM. (1997). Socioeconomic and Demographic Factors Are Associated with Worldwide Patterns of Stunting and Wasting of Children. J Nutr. 127:2302-9.

[11] Gavin, 2009; Hunger and malnutrition report, available at : (http://kidshealth.org/parent/misc/reviewers.html) (Accessed on October 2009)

[12] Gharib, N and Rasheed P, (2009). anthropometry and body composition of school children in Bahrain, Annals of Saudi Medical Journal.; vol 29, (4), pp 258-269.

[13] Gür E, Can G, Akkus S, Ercan G, Arvas A and Güzelöz S, et al. (2006). Is undernutrition a problem among Turkish school children?: Which factors have an influence on it? J Trop Pediatr. 52:421-6.

[14] Haboubi GJ, and Shaikh RB. A (2009).Comparison of the Nutritional Status of Adolescents from Selected Schools of South India and UAE: A Cross-sectional Study. Indian J Community Med. 34:108-11.

[15] Kliegman RM, Behrman RE, Jenson HB, Stanton BF, (2007). "chapter 43: Food insecurity, hunger, and undernutrition. In eds. Nelson Textbook of Pediatrics. 18th ed. Philadelphia, Pa: Saunders Elsevier.

[16] http://www.dietpowersoftware.com (accessed on 2010)

[17] http://www-01.ibm.com/software/analytics/spss/ (accessed on 2010)

[18] Juan F.,( 2006), Dietary habits and nutritional status of school aged children in Spain, Nutr. Hosp. v.21 n.3.

[19] Khuwaja S, Selwyn BJ and Shah SM. (2005).Prevalence and correlates of stunting among primary school children in rural areas of southern Pakistan. J Trop Pediatr. 51:72-7.

[20] Kimani-Murage EW, Kahn K, Pettifor JM, Tollman SM, Dunger DB and Gómez-Olivé XF, et al. (2010). The prevalence of stunting, overweight and obesity, and metabolic disease risk in rural South African children. BMC Public Health. 10:158-70.

[21] Leslie J and Jamison D, (1990) ; Health and nutrition considerations in education planning. 1. Educational consequences of health problems among school-age children, Food and Nutrition Bulletin, Volume 12, Number 3, September 1990

[22] Mikki N, Abdul-Rahim HF, Faisal Awartani F, and Holmboe-Ottesen G(2010). Prevalence and sociodemographic correlates of stunting, underweight, and overweight among Palestinian school adolescents (13-15 years) in two major governorates in the West Bank. [Last accessed on Aug 13]. Available from: http://www.biomedcentral.com/1471-2458/9/485 .

[23] Monteiro CA, D’Aquino Benicio MH, Conde WL, Konno S, Lovadino AL, and Barros AJ, et al.( 2010). Narrowing socioeconomic inequality in child stunting: The Brazilian experience, 1974-2007. Bull World Health Organ88:305-11.

[24] National Health and Nutrition Examination Survey II -- 
(NHANES II), Created by Jean Roth March 26, 2007

[25] Neumann C and Bwibo N, (1987). Example of stunting: Kenya project. Human Collaborative Research Support Program, USAID, Office of Nutrition.

[26] Ogden CL, Carroll MD, and Flegal KM. (2008). High body mass index for age among US children and adolescents 2003-2006. JAMA. 299:2401-5.

[27] Onis de M et al (2007). Development of a WHO growth reference for school-aged children and adolescents. Bulletin of the World Health Organisation, volume 85, No 9, pp 649732, September 2007.

[28] Osei A, Houser R, Bulusu S, Joshi T, and Hamer D, (2010). Nutritional status of primary schoolchildren in Garhwali Himalayan villages of India, Food Nutr Bull. Jun;31(2):22133.

[29] Perry, S. D. (2008).Comparison of Nutritional Intake of Home School Children and Public School Children: A Comparison Study, Master of Science Thesis, The Graduate School, College of Agriculture, University of Kentucky.
[30] Popkin, BM., Richards, MK.and Montiero, CA, (1996). stunting is associated with overweight in children of four nations that are undergoing the nutrition transition. Journal of Nutrition. ; vol 126, pp 3009-3016. .

[31] Renzaho A, Gibbons C, Swinburn B, Jolley D and Burns C;(2006) Obesity and undernutrition in sub-Saharan African immigrant and refugee children in Victoria, Australia.

[32] Shariff Z, Bond J, and Johson N , (2000) Nutritional Status of Primary School Children from Low Income Households in Kuala Lumpur, Mal J Nutr $6: 17-32$,

[33] Wang Y, Popkin B and Zhai F. (1998). The nutritional status and dietary pattern of Chinese adolescents, 1991 and 1993. Eur J Clin Nutr.;52:908-16.

[34] WHO,(1995).Physical Status: the Use and Interpretation of Anthropometry: Technical Report Series no. 854. Geneva: World Health Organization.

[35] WHO,(2005). Child obesity: Technical Report Series. Geneva: World Health Organization. 